\title{
INSOLUBLE SURFACE RESIDUES STUDIES ON CHEMICALLY AMPLIFIED POSITIVE RESIST FOR KrF EXCIMER LASER LITHOGRAPHY
}

\author{
SHIGEYASU MORI, TAKASHI FUKUSHIMA,TAKASHI SUGIHARA, JYUNKOU TAKAGI \\ ULSI Research Project Team, Central Research Laboratory, Sharp Corporation \\ 2613-1, Ichinomoto-cho, Tenri-city, Nara 632, Japan
}

\begin{abstract}
It is important to understand the forming mechanism of insoluble surface residues in chemically amplified positive resists, which is affected by process conditions. In order to clarify the forming mechanism, we investigated the diffusing behavior of hexamethyldisilazane (HMDS) in resist. A novel pattern formation technique is proposed, using the insoluble surface residues which are formed by exposure the HMDS vapor. Several factors in regard to the formation mechanism of the insoluble surface residues are indicated by the dissolution rate, and the FT-IR and XPS studies with variable process parameters. Resist sensitivities are affected by quenching acids which are generated by exposure. The forming mechanism of insoluble surface residues after exposure to HMDS vapor can be recognized by the forming of Si-O bonds and decreasing of the hydrogen bonds. A refined pattern profile with high contrast can be obtained by using the novel pattern formation technique.
\end{abstract}

\section{Introduction}

Chemically amplified positive resists are widely investigated, and expected to be used in actual device fabrication processes[1-5]. A few problems exist which are mainly affected by resist processes. The Post Exposure bake Delay(PED) is one of the most serious problems, which results sensitivity and pattern size control instability depending on the delay time after exposure[6-7]. Another problem is insoluble surface residues on resist surface[8-9]. Generally, the residues are caused by unstable acid generated by exposure, which diffuses in the resist and causes higher sensitivity, or it loses activity and causes lower sensitivity.

In order to solve these problems, it is important to understand the insoluble surface residue forming mechanism of chemically amplified positive resists. In this paper, we study the dissolution behavior, FT-IR spectra, XPS spectra, sensitivities, and replication properties of a resist and its 
exposure to hexamethyldisilazane(HMDS), which seems to affect the stability of the resist. Based on the results, we propose a novel dissolution mechanism and a pattern formation technique using the HMDS treatment.

\section{Experiment}

\subsection{Material}

Poly(4-vinylphenol) partially protected with t-butoxy-carbonyl (t-BOC-PVP) $(\mathrm{Mw}=13,000$, $\mathrm{t}$ BOC $=13 \%$ ) was obtained from Shinetu Chemical Co., Ltd. as a base polymer. Triphenylsulfonium trifluoromethanesulfonate was synthesized according to the literature[10] as an acid generator. Bisphenol A protected with t-BOC was synthesized according to the literature[11] as a dissolution inhibitor.

Resist solutions were prepared by dissolving the matrix copolymer (16 wt.\%) in 1-Methoxy-2Propanol followed by the addition of the required amount of photo acid generator $(0.8 \mathrm{wt} . \%)$ and dissolution inhibitor (3.2 wt.\%): The solution was filtered through Teflon membrane filters.

\subsection{Measurement}

FT-IR analysis was done with a FT530® from Horiba Co., Ltd. XPS analysis was done with Kratos Analytical Instrument model XSAM $800 ®$. Film thickness was measured with a Tencor Alpha-Step $200 \AA$ or a Nanometrics/AFT $®$. A dissolution rate monitor (leapset ${ }^{\circledR}$ ) from General Signal Japan was used to determine the dissolution characteristics. Developed images were platinum coated and analyzed on a Hitachi model S-900® scanning electron microscope (SEM).

\subsection{Lithographic evaluation}

Si substrates were primed with hexamethyldisilazane (HMDS) using a coater and then coated with the resist. The wafer was then prebaked at $100^{\circ} \mathrm{C}$ for $120 \mathrm{sec}$ and exposed on a deepUV stepper (NA :0.45) equipped with a $\mathrm{KrF}$ excimer laser using a wavelength of $248 \mathrm{~nm}$. The exposed wafer was post exposure baked at $80^{\circ} \mathrm{C}$ for $60 \mathrm{sec}$, developed for $60 \mathrm{sec}$ in $2.38 \%$ tetramethyl ammonium hydroxide (TMAH) aqueous base (NMD-W® from Tokyo Ouka Kogyo Co., Ltd.), and rinsed with water for $20 \mathrm{sec}$.

\section{Results and Discussion}

\subsection{Improvement of pattern formation}

Figure 1(a) shows the pattern profile of this resist formed by the conventional process. We can recognize the degradation by the tapered pattern profile. In order to improve this pattern profile, it is effective to form the insoluble surface residues on the resist surface, quenching the acid generated by exposure. Figure 1(b) shows the pattern profile of this resist with the exposure to the HMDS vapor 
for one second before post exposure bake(PEB). It is clear that the insoluble surface residues are formed and the tapered pattern profile is improved by the HMDS process. The profile is a reversed triangle on the resist top. Optimization of the parameters is necessary, and will be done in future research. The sensitivity of the resist with the HMDS process is about $1 / 2$ that of the conventional process.

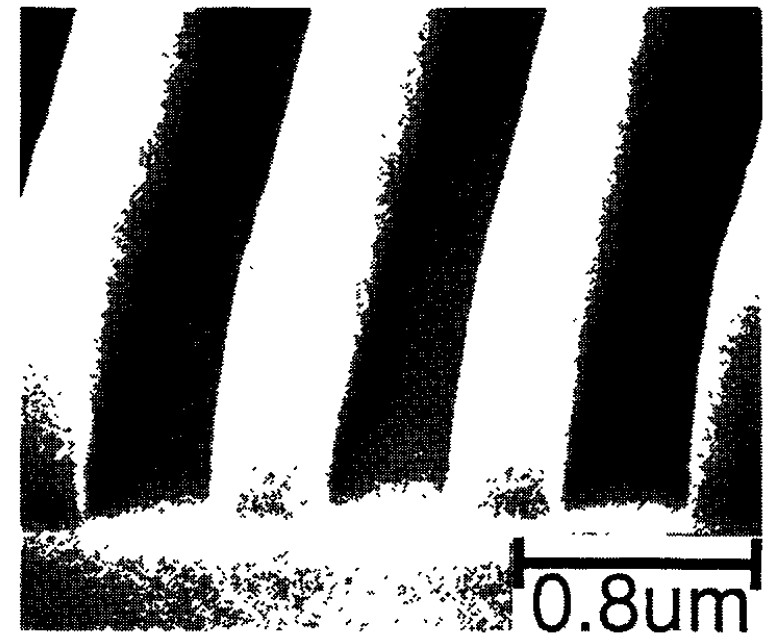

(a)

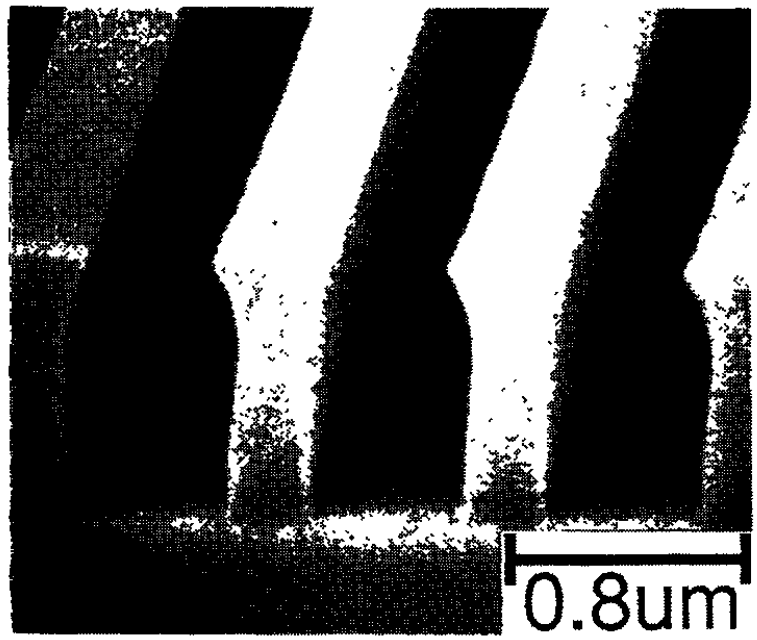

(b)

Fig. 1. SEM micrograph of $0.4 \mathrm{um}$ geometry obtained by KrF excimer laser stepper cxposure.

(a) conventional process with dosage $=28.5 \mathrm{~mJ} / \mathrm{cm}^{2}$.

(b) HMDS treatment for $1.0 \mathrm{sec}$ with $\operatorname{dosagc}=51 \mathrm{~mJ} / \mathrm{cm}^{2}$.

Figure 2 shows the stability of the resist sensitivity which is threshold energy (dosage to clear out the resist residues) of the conventional and advanced HMDS processes with time in clean room after exposure. The resist sensitivity with the conventional process decreases as the Post Exposure bake Delay(PED) time increases. The photo-generated acids diffuse and finally lose their activity. On the other hand, the sensitivity with the advanced process, which exposes the resist in the HMDS vapor for one second after exposure, is stable. The variation is only within $+/-10 \%$ of the initial sensitivity value. However, with a longer HMDS treatment $(2.5 \mathrm{sec})$, the sensitivity increases as the PED time increases. These results indicate that there are some $1-B O C$ groups decomposed without PEB, and that this decomposition reaction proceeds as the PED time increases. It is necessary to optimize the HMDS treatment time to observe the highest stability of resist sensitivity.

Figure 3 shows the sensitivity curves of the conventional and advanced HMDS treatment processes. The resist sensitivity depends on the HMDS treatment time. The resist contrasts with the HMDS treatment are higher than with the conventional process. This supports the claim that the acids generated by exposure are quenched by HMDS ( Scheme 1 ). However, the solubility of the insoluble surface residues formed by the HMDS treatment depends on the exposure dosage. If there 
is only one mechanism of acid quenching by HMDS, the dissolution of insoluble surface residues will not change. The $t-B O C$ substitution group of matrix copolymer and dissolution inhibitor in the resist, control the dissolution inhibition. We believe that insoluble surface residues are formed by a new chemical species as well as by acid quenching.

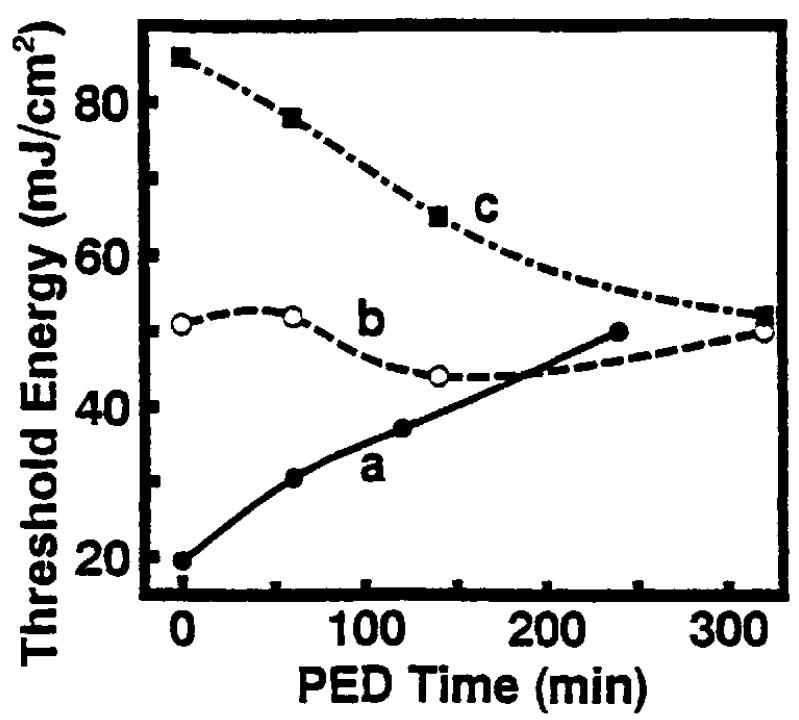

Fig. 2. PED effect curves obtained with various HMDS treatment conditions.
(a) conventional, (b) HMDS 1.0sec

(c) HMDS $2.5 \mathrm{sec}$

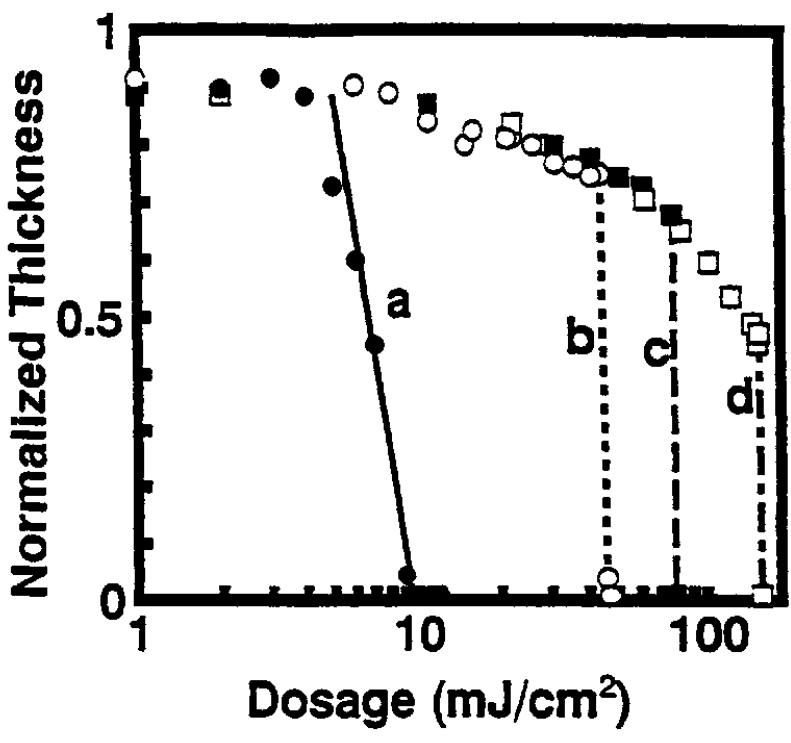

Fig. 3. Exposure characteristic curves obtained with various HMDS treatment conditions.

(a) conventional, (b) HMDS $1.0 \mathrm{sec}$

(c) HMDS 2.5sec, (d) HMDS 5.0 sec

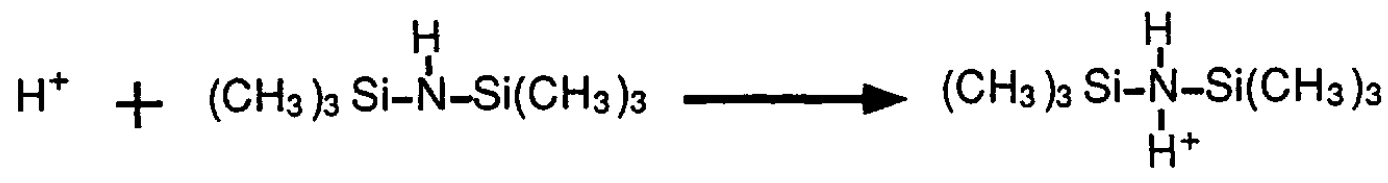

Scheme 1. Mechanism for photo-generated acid quenching by HMDS.

\subsection{Dissolution characteristics of insoluble surface residues}

Figure 4 shows the dissolution characteristics of the resist with the conventional and HMDS treatment processes. In (a), the conventional process resist has a uniform dissolution rate and there is no insoluble residue layer. On the other hand, the HMDS treatment processed resist has an insoluble surface residue layer and the resist dose not have a uniform dissolution rate. The dissolution rate of the HMDS treatment process, except for that corresponding to the insoluble surface residues, is similar to the conventional process rate. It is certain that the $\mathrm{t}-\mathrm{BOC}$ groups are decomposed by the photo-generated acids on these layers. The dissolution rate of insoluble surface residues formed during a 120 second HMDS vapor treatment after exposure, is higher than unexposed resist (see figure). This result suggests that insoluble surface residues are formed by a new chemical species which can not be due to $t-B O C$ groups. 


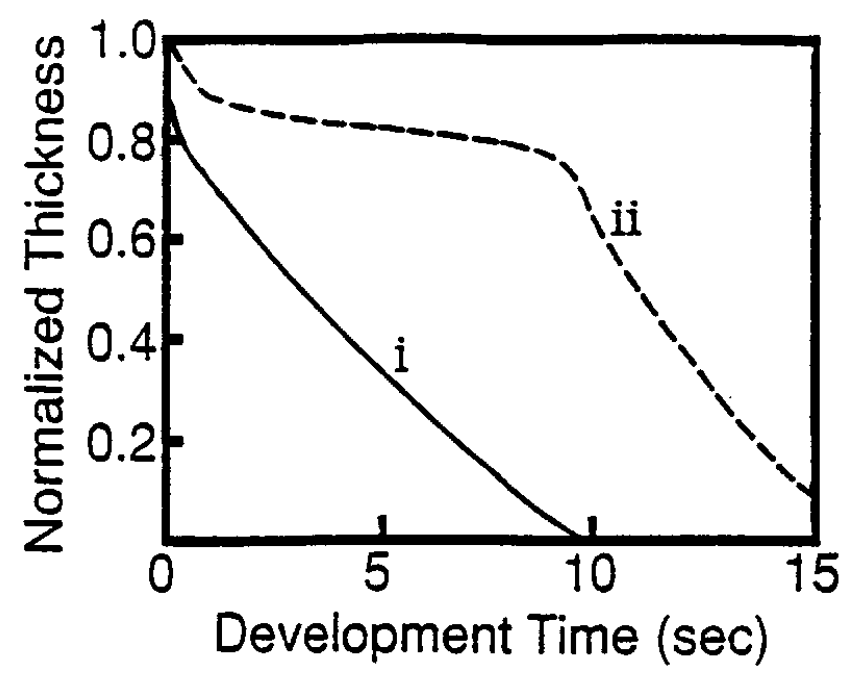

(a)

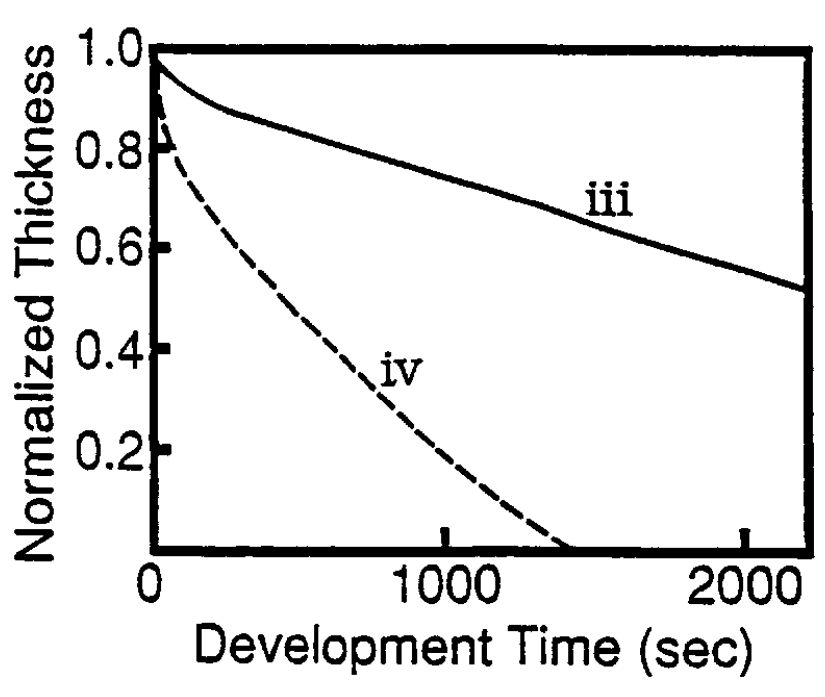

(b)

Fig. 4. Dissolution rates of the resist with various process conditions.

(i) exposed resist (dosage $=100 \mathrm{~mJ} / \mathrm{cm}^{2}$ ) with conventional process

(ii) exposed resist (dosage $=100 \mathrm{~mJ} / \mathrm{cm}^{2}$ ) with HMDS $5.0 \mathrm{sec}$ process

(iii) unexposed resist (dosage $=0 \mathrm{~mJ} / \mathrm{cm}^{2}$ ) with conventional process

(iv) exposed resist (dosage $=100 \mathrm{~mJ} / \mathrm{cm}^{2}$ ) with HMDS $120 \mathrm{sec}$ process

\subsection{New chemical species analysis}

In order to analyze the insoluble surface residues, we measured the IR spectra of the unexposed resist and the insoluble surface residues which were formed in the HMDS vapor by the exposure for 120 seconds after exposure. Figure 5 shows these spectra. On these spectra, there is no difference in the absorption band of $1750 \mathrm{~cm}^{-1}$ based on the $\mathrm{C}=\mathrm{O}$ bond. This suggests that the $\mathrm{t}-\mathrm{BOC}$ groups on the exposed area are not decomposed by the HMDS treatment. We consider that there is a new chemical species, which promotes resist dissolution.

Figure 6(a) shows the difference characteristics of the IR spectra between before the HMDS treatment and after the HMDS treatment for $120 \mathrm{sec}$ on unexposed resist. An absorption band of $1100 \mathrm{~cm}^{-1}$ based on the Si-O bond is increasing after HMDS treatment. It suggests to formation of $\mathrm{Si}-\mathrm{O}$ bonds. Also, an absorption band of $3300 \mathrm{~cm}^{-1}$ based on the $\mathrm{O}-\mathrm{H}$ bond is increasing. There is the possibility to form a new chemical species relating to the formation of Si-O bonds. Figure $6(\mathrm{~b})$ shows the difference characteristics of IR spectra between before HMDS treatment on unexposed resist and after HMDS treatment for $120 \mathrm{sec}$ on exposed resist. An absorption band of $3300 \mathrm{~cm}^{-1}$ based on the $\mathrm{O}-\mathrm{H}$ bond is stronger than in the (a) spectrum. The new chemical species may be remarkably formed in the presence of acid. This suggests that hydrogen bonds in the resist decreased. 


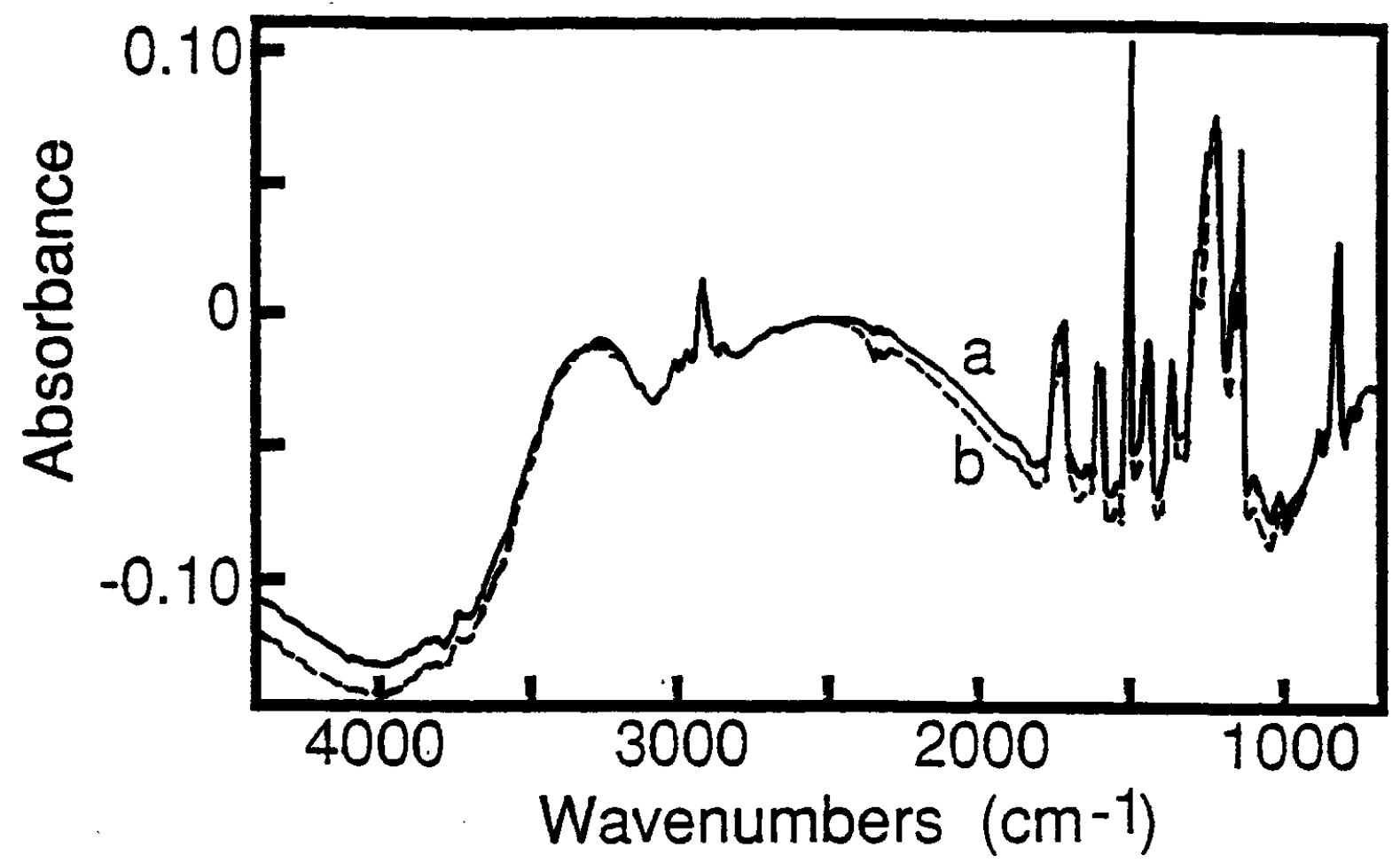

Fig. 5. IR spectra of the resist, (a) unexposed, (b) exposed $\left(100 \mathrm{~mJ} / \mathrm{cm}^{2}\right)$ with HMDS treatment for $120 \mathrm{sec}$.

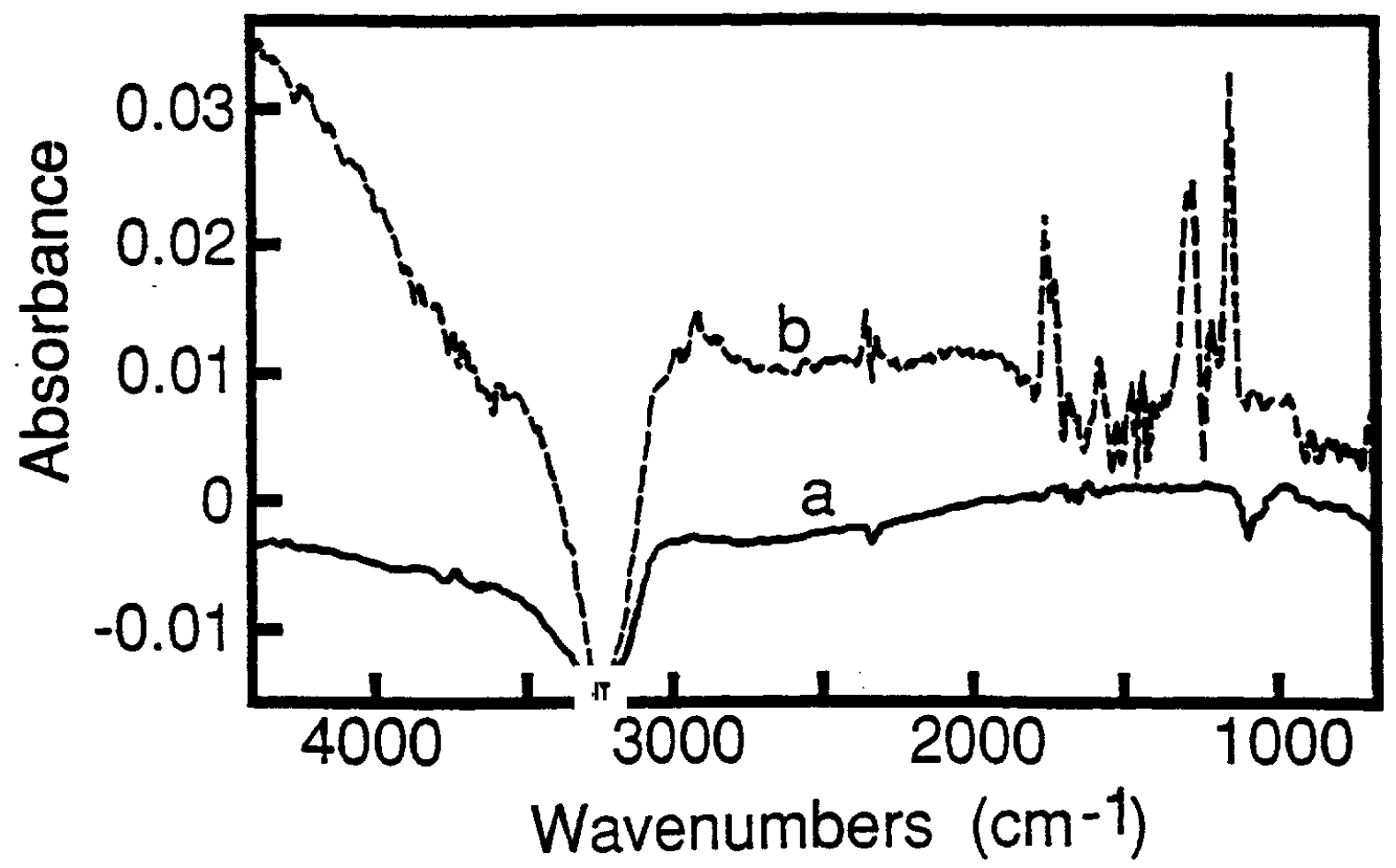

Fig.6. Difference IR spectra of the resist, (a) between before the HMDS urcatment and after the HMDS treatment for $120 \mathrm{sec}$ on unexposed resist, (b) between before HMDS treatment on uncxposed resist and after HMDS treatment for $120 \mathrm{sec}$ on exposed $\left(100 \mathrm{~mJ} / \mathrm{cm}^{2}\right)$ resist. 
Figure 7 shows the XPS spectra of bare $\mathrm{Si}$, the conventional unexposed resist, and the unexposed resist with the HMDS treatment for $30 \mathrm{sec}$. On the spectrum of bare Si (a), there are the peak (kinetic energy $=1155 \mathrm{eV}$ ) which can be assigned to $\mathrm{Si} 2 \mathrm{p} 3 / 2$ of $\mathrm{Si}-\mathrm{Si}$, and the $4 \mathrm{eV}$ shifted peak (kinetic energy $=1151 \mathrm{eV}$ ) which can be assigned to $\mathrm{Si} 2 \mathrm{p} 3 / 2$ of $\mathrm{SiO}_{2}$. On the other hand, the unexposed resist (c) with HMDS treatment for $30 \mathrm{sec}$ has the $3 \mathrm{eV}$ shifted peak (kinetic energy $=1152 \mathrm{eV}$ ) which can be assigned to $\mathrm{Si} 2 \mathrm{p} 3 / 2$ of $\mathrm{Si}$ combined with a organic compound. This supports the above discussion.

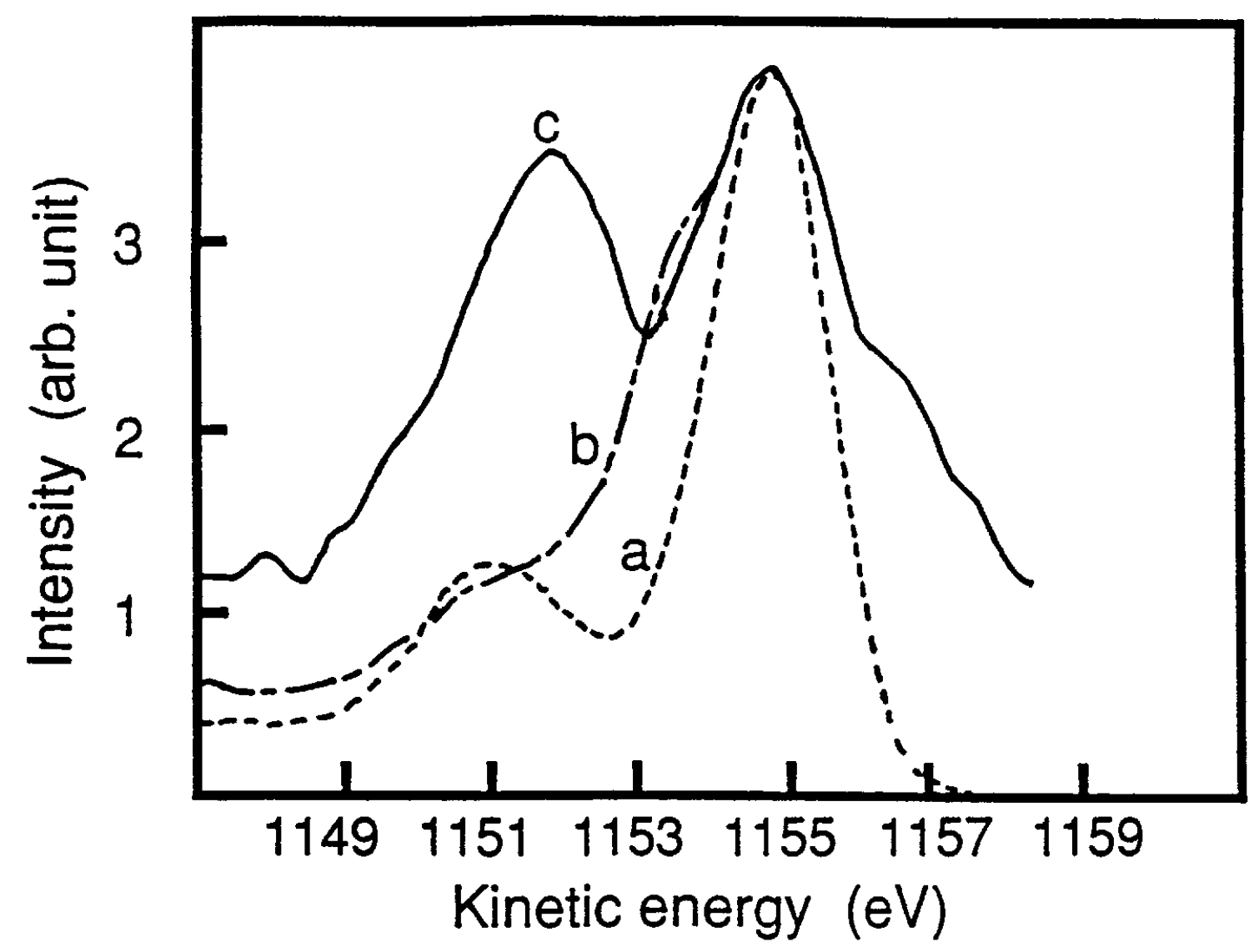

Fig. 7. XPS spectra of the resist, (a) bare Si, (b) conventional unexposed resist, (c) unexposed resist with HMDS treatment for 30 sec.

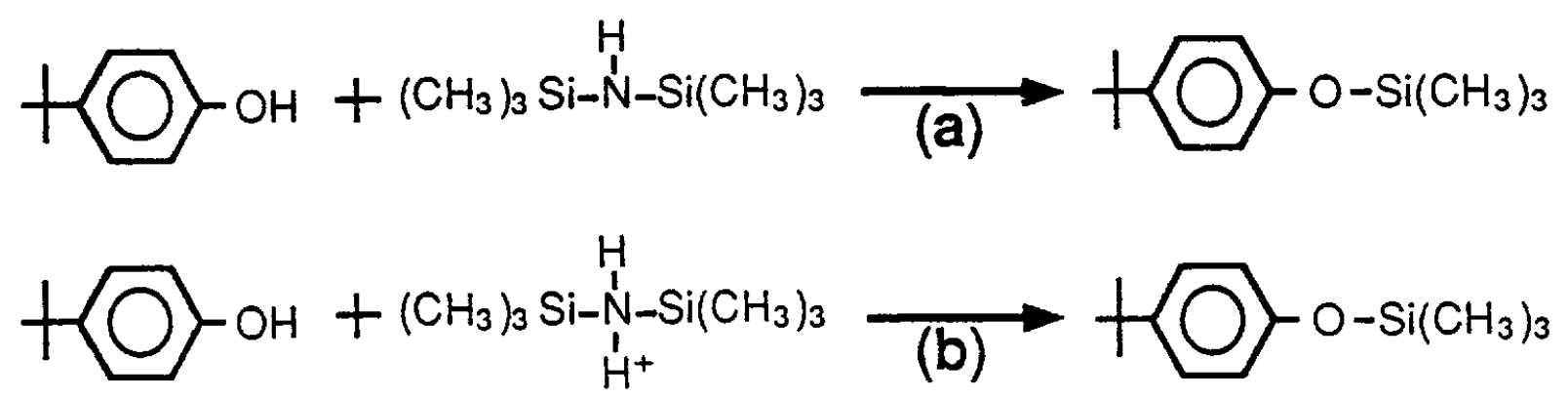

Scheme 2. Mechanism for formation of surface residue by HMDS. 
We consider that insoluble surface residues will be formed according to the mechanism which O$\mathrm{H}$ bonds are exchanged to Si-O bonds by HMDS following scheme 2 (a) and/or (b) and the hydrogen bonds in the resist decrease. The results, where insoluble surface residues are remarkably formed in the presence of acid on exposed resist, suggest scheme 2 (b) reactions demonstratively.

\section{Conclusion}

For chemically amplified positive resist, we indicate that the insoluble surface residue formation in HMDS vapor treatment after exposure, is useful for improved pattern profile and stable pattern formation. Also, we clarified the acid quenching mechanism by HMDS, and the forming mechanism of insoluble surface residues caused Si-O bond formation and hydrogen-bond decrease.

\section{Acknowledgments}

The authors would like to thank Dr. N. Hashizume(Sharp CRL General Manager) and T. Sakurai(Sharp CRL Deputy General Manager) for their continuous encouragement during this work, and Shinetu Chemical Co., Ltd. for the supply of polymer.

\section{References}

1. J.M. Kometani, O.Nalamasu, E. Reichmanis, R.S. Kanga, L.F. Thompson, and S.A. Heffner, J. Vac. Sci. Technol.B 8(1990)1428.

2. R. Sezi, H. Borndorfer, R. Leuschner, C. Nolscher, M. Sebald, H. Ahne, and S. Birkle, Jpn. J. Appl. Phys. 30(1991)3108.

3. M, Sakano, T. Ito, and Y. Yamashita, Jpn. J. Appl. Phys. 30(1991) 3116.

4. A. Oikawa, S. Miyata, K. Maeda, H. Tanaka, and K. Nakagawa, Proc. SPIE $1672(1992) 149$.

5. H. Roschert, R. Dammel, Ch. Eckes, K. Kamiya, W. Meier, K.J. Przybilla, W. Spiess, and G. Pawlowski, Proc. SPIE 1672(1992)157.

6. M. Cheng, O. Nalamasu, A.G. Timko, V. Pol, J.M. Kometani, E.Reichmanis, and L.F. Thompson, J. Vac. Sci. Technol. B 9 (1991) 3374.

7. W.D. Hinsberg, S.A. MacDonald, N.J. Clecak, and C.D. Snyder, Proc. SPIE 1672(1992) 24

8. D.J.H. Funhoff, H. Binder, and R. Schwalm : Proc. SPIE 1672 (1992)46.

9. T.-F. Yeh, H.-Y. Shih, A. Reiser, M.A. Toukhy, and B.T. Beauchenmin, Jr., J. Vac. Sci. Technol. B 10(1992)715

10. S.S. Kulp, and R. Szarko, J. Org. Chem., 53(1988)5573

11. F. Houlihan, F. Bouchard, J.M.J. Frechet, and C.G. Willson, Can. J. Chem., 63(1985)153 